\title{
Origen y decadencia del gamonalismo en la sierra ecuatoriana
}

\author{
Hernán Ibarra Crespo
}

Centro Andino de Acción Popular, Quito

Este artículo analiza la trayectoria histórica del gamonalismo en la sierra ecuatoriana. Aunque homologado con el caciquismo mexicano y el coronelismo brasileño, tiene rasgos específicos. En el Ecuador es posible reconstruir el significado del gamonalismo en el lenguaje político y como modalidad de dominación tradicional. Por una parte, se realiza un rastreo y análisis del uso del término en distintos momentos históricos entre los siglos XVIII y XX. Por otra parte, se efectúa un abordaje del origen y declinación de esta forma de poder. Se aspira a construir un marco interpretativo que aporte a la comprensión de los fundamentos agrarios de la constitución del Estado ecuatoriano y las formas de dominación étnica.

PALABRAS ClaVE: Gamonalismo, dominación étnica, estado ecuatoriano, poder local.

This article analyzes the historical path of gamonalismo in Ecuadorian highlands. Although it could be alike to Mexican caciquismo and Brazilian coronelismo, gamonalismo had its specific forms. In Ecuador it is possible to reconstruct its meaning in political terms, as a form of traditional domination. The use of this particular term is analyzed in different historical moments between the $18^{\text {th }}$ and $20^{\text {th }}$ century; focusing on the origin and decline of this local power. The aim is to build an interpretative frame in order to understand agrarian sources of Ecuadorian state development and ethnic domination.

KEYwords: Gamonalismo, ethnic domination, Ecuadorian state, local power.

\section{Introducción}

El poder político tiene una historia en la que hay un origen, una trayectoria y un declive. Las formas locales de poder local rural expresan una trama constitutiva de relaciones y actores que en la larga duración muestran cambios y variaciones. Tales modificaciones tienen su propio ritmo temporal en interacción con procesos nacionales de índole más amplia. Es así que emergen representaciones sociales y políticas del poder local que son vehiculizadas a través del lenguaje. Se convierten en palabras clave que remiten a una etimología, significados y contextos. Por ello el gamonalismo evidencia también los significados cambiantes que surgieron en las configuraciones de los actores y prácticas del poder local.

En los países andinos, la modalidad de poder local rural conocida como gamonalismo, fue objeto de relativa atención hasta los comienzos de 
las reformas agrarias, en los años sesenta, cuando esta forma de poder se hallaba en crisis o decadencia. Una imagen muy influyente, fue producida por el pensamiento y la novela indigenista a partir de los años veinte. $\mathrm{La}$ identificación del gamonalismo como una forma de dominación y extorsión a la población rural, fue un tópico del discurso agrarista y de izquierda que se hallaba incorporado al lenguaje político.

El gamonalismo supone la existencia de los gamonales, los personajes que ejercen el poder local. El término gamonal, tanto en el uso político como en su manejo conceptual, ha sido virtualmente abandonado. Persiste tenuemente en el lenguaje político, pero ya de una forma limitada y accidental. ${ }^{1}$ A pesar de la importancia del tema, no hay todavía una reflexión global que indague lo que fue el gamonalismo como forma del ejercicio del poder a nivel local en sociedades que tenían características de predominio rural y densas poblaciones indígenas. ${ }^{2}$ Cualquier estudio de las formas modernas de poder local tendría al menos que remitirse a las formas anteriores, buscando su contraste con lo nuevo, las prolongaciones de lo antiguo, o sus huellas.

1 En un conflicto ocurrido en Cayambe que confrontó al alcalde Diego Bonifaz con la población urbana por las tarifas de agua potable, este fue denominado gamonal. Un cartel que aparece en una fotografía que acompaña a una nota de prensa, dice: "Rechazar las actitudes y prácticas prepotentes del alcalde gamonal en contra de los cayambeños". No es sorprendente entonces que el término haya aparecido motivado por un conflicto local de poder.("Tercer día de la toma de una iglesia en Cayambe", El Comercio, 7/2/2002).

2 Recientemente, se ha aludido al gamonalismo como parte de una tradición constitutiva de la matriz política serrana del Ecuador. Ver Bustamante, Fernando: "Los polos de la crisis: su racionalidad y horizonte", Ecuador Debate, N. ${ }^{\circ}$ 47, Quito, 1999, págs. 27-28. Algunos estudios que han abordado el poder local rural, son los de Fauroux, Emmanuel: "Poder regional e instituciones regionales en la provincia de Loja desde principios del siglo XX: ejes de una investigación", Cultura, vol. V, N. ${ }^{\circ} 15$, Quito, 1983, págs. 235-253, donde no se recurre a la noción de gamonalismo, y se analiza el auge y la decadencia de una oligarquía terrateniente regional; Montes del Castillo, Angel: Simbolismo y poder. Un estudio antropológico sobre compadrazgo y priostazgo en una comunidad andina, Anthropos, Barcelona, 1989, que estudia los cambios del poder en una parroquia rural de Azuay a comienzos de los años setenta del siglo XX; Bernard, Carmen: "El cura párroco, los indígenas y el poder local: etnohistoria política del Azuay", Acción, N. ${ }^{\circ}$ 10, 1987, Quito, págs.6-15, análisis ubicado en el período colonial tardío, que anuncia el conflicto entre autoridades civiles y eclesiásticas en torno al control de la población indígena; Sylva, Paola: Gamonalismo y lucha campesina, Abya-Yala, s.1., 1986, se refiere explícitamente como expresión de gamonalismo a los sistemas agrarios dominados por la hacienda en Guamote durante los años cincuenta y sesenta; y sus prolongaciones hacia la esfera política regional. En un estudio referido a la costa del Ecuador, Ojeda utilizó la noción de "micro-oligarquía". Ojeda, Lautaro: "Estructura productiva y micro-oligarquía durante la época cacaotera: el caso del Milagro", Ciencias Sociales, núms. 10-11, 1979, Quito, págs. 11-28. Para otra región de la costa ecuatoriana, ver Ferreira, Maria Nazareth: Manabí: historia e comunicacao atraves de sua literatura, Tesis, USP, Sao Paulo, 1985, donde se estudian las relaciones de poder rural en las primeras décadas del siglo XX, recurriendo a la literatura costumbrista manabita 
Aquí desarrollo una visión de cómo se constituyó esta forma de poder, así como el uso del término gamonal en el lenguaje político y de las ciencias sociales. Para eso, trataré de explicar una realidad social, el proceso histórico de constitución del poder local rural en zonas indígenas, y las concepciones cambiantes que surgieron para definir el gamonalismo.

La evolución del gamonalismo como parte del lenguaje político es una cosa, y otra, son las interpretaciones del poder local rural que han recurrido al uso del término. Ha tenido un uso creciente desde los comienzos del siglo $\mathrm{XX}$, hasta su declinación en el lenguaje en los años setenta. ${ }^{3}$ Esto puede tener una explicación: al cambiar la estructura agraria y desaparecer o disminuir objetivamente la antigua clase terrateniente y la trama de antiguo régimen, se extinguían los sujetos sobre los que se había construido la denominación que, insistamos, siempre estuvo muy polítizada o ideologizada.

Lo que aquí argumento es que el gamonalismo es una forma de poder político local rural resultante de la vigencia de una estructura estamental o de castas, en la que se ha "naturalizado" la dominación étnica. Su sostén son las sociedades rurales en las que existe subordinación campesina por el predominio de sistemas agrarios en los que impera la gran propiedad. Sin embargo, hay otra variante del gamonalismo que se halla vinculada al capital comercial y los mecanismos despóticos o coactivos de constitución de las relaciones de mercado. En este caso, incluso puede haber una mejor distribución de la tierra y la gran propiedad rural no ser importante. Todo ello supuso la existencia de variantes locales, de acuerdo a las relaciones agrarias y étnicas implicadas de modo particular como posiciones y campos de fuerzas.

Trataré de conceptualizar el gamonalismo como una forma de poder difusa y descentralizada que se basa en la segmentación del funcionamiento de la sociedad agraria, con sus particularidades regionales, locales y características étnicas. Así el gamonalismo podría ser interpretado también dentro de un proceso de diseminación del poder, con sus zonas, lugares y eslabonamientos; y alude a los fundamentos agrarios de la constitución del Estado, es decir, a la trama de relaciones sociales y simbólicas

3 En el clásico estudio sobre la estructura agraria del Ecuador, CID: Tenencia de la tierra y desarrollo socio- económico del sector agrícola. Ecuador, Unión Panamericana, Washington, 1965, págs. 96-98, se describe la estructura de poder rural con dominio terrateniente y sus vínculos con pueblos mestizos y autoridades religiosas en amplias zonas de la sierra ecuatoriana. En tanto se trataba de un momento conflictivo en el que se realizó el estudio, al describir los conflictos laborales en las haciendas, un testimonio sobre la provincia de Chimborazo, se remite a los gamonales y las "haciendas gamonales" (pág.96) 
que en las zonas rurales conformaban las instituciones estatales y privadas de dominación.

\section{Caciquismo y coronelismo}

Fenómenos análogos al gamonalismo, son el caciquismo mexicano y el coronelismo brasileño que también han sido conceptualizados como formas de dominación rural en la tradición de las ciencias sociales de América Latina. La apabullante bibliografía existente sobre el caciquismo mexicano, ha descrito a estos personajes como intermediarios políticos en la formación del Estado mexicano. ${ }^{4}$ Una famosa novela de Jorge Amado, Gabriela, clavo y canela, tiene como uno de sus personajes a un coronel en una etapa de decadencia ante la aparición de una nueva forma de dominación que le reemplaza. ${ }^{5}$

En las imágenes más recurrentes sobre las formas de dominación rural en América Latina, se suele hablar del caciquismo, el mismo que ha sido generalmente definido como la capacidad de control de una esfera de poder local o regional, con mecanismos clientelares o despóticos. El cacique es así, la figura que organiza un poder local. Un intermediario que tiene una capacidad de control del orden político local, sustentándose en redes sociales de compadrazgo y parentesco. Por lo menos en el caso mexicano, el caciquismo se presenta como un fenómeno que mantiene vigencia, y que se encuentra en la base de la organización del poder estatal. Sus características despóticas han sido subrayadas por los estudiosos, y se hallaría en el centro de los conflictos sociales y étnicos regionales actuales. ${ }^{6}$

El coronelismo, ha sido designado como un producto de la debilidad del Estado brasileño a nivel local, que requería de intermediarios para controlar a la población rural. Pero al mismo tiempo, los coroneles eran los agentes de la penetración del Estado. ${ }^{7}$ Estos actores aparecieron a fines del siglo XIX como consecuencia de la estructuración de las guardias nacio-

4 Ver: De la Peña, Guillermo: "Poder local, poder regional: perspectivas socio-antropológicas”, en Padua, Jorge y Alain Vaneph, Poder local y poder regional, El Colegio de México/CEMCA, México D.F., 1986, págs. 27-56.

5 Amado, Jorge: Gabriela, clavo y canela, El Mundo, Madrid, [1958] 1999.

6 Warman, Arturo: "Chiapas hoy", en Trejo Delarbre, Raúl (comp.), Chiapas. La guerra de las ideas, Ed. Diana, México D.F., 1994, 2a. imp, pág. 154.

7 Murilo de Carvalho, José: "Mandonismo, coronelismo, clientelismo: Uma discussao conceitual”, Dados, vol. 40, n. ${ }^{2}$, Rio de Janeiro,1997, págs. 229-250. 
nales que otorgaron a los terratenientes el título honorario de coronel. En las primeras décadas del siglo $\mathrm{XX}$, tienen un radio de acción municipal y eran decisivos como intermediarios políticos. Hay una discusión acerca de si el coronelismo es propio del período histórico que va desde fines del siglo XIX hasta 1930, o si se mantuvo modificado en la política brasileña hasta bien entrado el siglo XX.

Un antecedente que debe ser mencionado por su influencia, es la reflexión de Joaquín Costa sobre el caciquismo español. Define tres sujetos que ejercen la dominación: oligarquías, caciques y gobernadores. Las oligarquías eran los notables pertenecientes a los núcleos centrales del poder, mientras que los caciques se encontraban en los diversos escalones del poder local. Por tanto, entre oligarquías y caciques, habría que pensar en una relación poder central-poder local. Todas estas formas de poder aparecían a los ojos de Costa como fruto del atraso español, o más ampliamente, como la ausencia de un Estado democrático. Por eso, su ideal era el de una democracia con ciudadanos. Uno de sus temas es la ausencia de ciudadanía en los medios rurales ${ }^{8}$.

La eliminación del caciquismo, según Costa, solo podría provenir de una reforma hecha desde arriba con un programa modernizador basado en la educación, la intervención estatal, reforma agraria, políticas laborales y sociales modernas. Una parte importante del cambio propuesto es una suerte de municipio social, con el desarrollo de servicios públicos locales. La propuesta de Costa, era un camino distinto al que podían proponer sectores reformistas y radicales empeñados en una movilización campesina que promoviera un cambio desde abajo.

Las semejanzas y diferencias de estas formas locales de poder, tienen como eje explicativo el despotismo rural surgido de situaciones de desigualdad social. Las modalidades de dominación tradicional, han tenido históricamente su sustento en ordenes sociales y políticos jerárquicos. Por ello es importante detenerse en el concepto de dominación patrimonial para entender las formas de ejercicio del poder local. Se trata básicamente de una prolongación de los intereses privados hacia el ámbito político o, más precisamente, de una confusión de lo público con lo privado que descansa en la falta de autonomía del ejercicio de las funciones estatales de las funciones privadas. Es un orden político que establece como fundamento la

8 Costa, Joaquín: "Oligarquía y caciquismo como la forma actual de gobierno en España" [1902], en Oligarquía y caciquismo. Colectivismo agrario y otros escritos, Alianza Ed., Madrid, 1973, 3a. ed., pág. 15-45. Este texto fue producto de una encuesta que Costa hizo desde El Ateneo de Madrid. 
tradición y las costumbres que crean nexos que pueden teñirse de fuertes lealtades. ${ }^{9}$ Dice Weber que "El patrimonialismo es compatible con la economía cerrada y con la economía basada en el cambio, con una estructura agraria pequeño burguesa o señorial, con la ausencia o la presencia de una economía capitalista". ${ }^{10}$ Hay que insistir en que se trata de una dominación que descansa en una diferenciación étnica en la que el poder se halla controlado por blancos y mestizos. Por tanto, se trata de un patrimonialismo apoyado en la dominación étnica.

Desde la década de 1960, se adoptó la perspectiva del clientelismo para el estudio del poder local. La noción de clientelismo, surgida del estudio de la política en sociedades rurales, tiene como sus elementos definitorios la relación de desigualdad social, el intercambio de bienes y servicios, así como concepciones de reciprocidad que permiten funcionar a una relación entre patronos y clientela. ${ }^{11}$ El modo clientelístico de actuación de la política, puede realmente impregnar todas las estructuras políticas, aunque de hecho, se pone más atención al funcionamiento clientelar a nivel local. ${ }^{12}$ Y con más frecuencia, dándole al clientelismo un especificidad de operación en sociedades rurales.

Este tipo de relaciones ocurren por la debilidad del Estado central que se ve obligado a delegar el control en intermediarios que suplen las carencias estatales. Esta debilidad se traduce en lo que Gellner llama una "centralización incompleta", que se caracteriza por un control parcial del territorio que hace que el Estado entregue o delegue poderes en determinados agentes. Aunque también el Estado puede controlar el territorio pero carecer de recursos para lograr la prestación de servicios. Por eso, surgen los intermediarios entre el poder local y el poder central, sin los cuales este carece de eficacia. En contraste, un Estado muy centralizado o con poderes difusos,

9 Weber, Max: Economía y sociedad, Fondo de Cultura Económica, Buenos Aires, [1922] 1992, págs. 753-847.

10 Ibídem, pág.829.

11 Duncan Powel, John: "Peasant society and clientelistic politics", American Political Science Review, vol. 64, ‥ㅇ 2, 1970, pág.412.

12 La bibliografía sobre el clientelismo es muy amplia. Una revisión la efectúan Piselli, Fortunata: "Il network sociale dell' analisi del potere e dei processi politici,"en Stato e Mercato, N. ${ }^{\circ}$ 50,1997; y , Moreno Luzón, Javier: "El clientelismo político: historia de un concepto multidisciplinar, Revista de Estudios Políticos, N. ${ }^{\circ}$ 105, Madrid, 1999. La investigación sobre México y Brasil está recogida por Roniger, Luis: "Caciquismo and Coronelismo: contextual dimensions of patron brokerage in México and Brazil", en Latin American Research Review, Vol. XXII, n. ${ }^{\circ}$ 2, 1987, págs. 71100. Sobre el clientelismo en medios urbanos, ver Burgwal, Gerard: Struggle of the poor. Neighborhood organization and clientelist practice in a Quito squatter settlement, CEDLA, Amsterdam, 1995. 
crea un ambiente poco propicio para las relaciones patrón cliente. ${ }^{13} \mathrm{El}$ asunto es si la noción de clientelismo puede ser útil para tratar las formas de poder local rural como el gamonalismo que tiene su soporte en la dominación étnica. Además, es conveniente no confundir lo que en la tradición antropológica se llamó relaciones patrón-cliente al estudiar las relaciones laborales y políticas en las haciendas tradicionales de América Latina. Esto es algo que queda enunciado a la espera de estudios que establezcan el clientelismo como un concepto de alcance histórico, a más de que recupere el papel más activo del lado subordinado de la relación clientelar. ${ }^{14}$

\section{Los orígenes y trayectoria del gamonalismo}

Se puede fechar a partir de 1920 la generalización del uso de la denominación gamonal como una expresión para definir al ejercicio del poder local en el Ecuador; aunque la primera referencia con la que me he topado, está ubicada en el siglo XVIII, cuando el vocablo gamonal, apareció mencionado en un juicio de la sublevación de indios de Riobamba ocurrida en 1764. Con esta palabra se estaba designando a algún sector dominante. No quedaba claro que en esa época se refirieran a algún personaje que ejerce el poder local. Sin embargo es sorprendente que la palabra ya haya sido usada en la época colonial. ${ }^{15}$ Pablo Macera, registró el término gamonal en Perú, en 1863, tal como había sido empleado en una revista que se encargó de definirlo como un personaje que basaba su poder en el control que le daba la tierra. Esta definición, con ciertas variantes, se mantendrá en el tiempo.

"La lengua castellana da el nombre de gamonal a un terreno que abunda en plantas afrodillas. Pero algunos pueblos americanos, ampliando la idea y tomando por extraña analogía y pícaramente al propietario por la propiedad, llaman gamonal (por no decir capataz o cacique) al hombre rico de un lugar pequeño, propietario de las tie-

13 Gellner, Ernest: "Patronos y clientes", en Gellner, E. et.al., Patrones y clientes, Ed. Jucar, Madrid, 1985, págs. 13-14.

14 En esta dirección se halla el trabajo de Auyero, Javier: "'From the client's point(s) of view": how poor people perceive and evaluate political clientelism", Theory and Society, vol. 28, 1999, págs. 297-334.

15 Archivo Nacional de Colombia. Indios de Riobamba. Autos sobre la grave sublevación de estos indios y otras doctrinas de su jurisdicción, a quienes se pretendía numerar, Microfilm. rollo. 5. 1. f. 001. La palabra gamonal aparece una sola vez en el documento y no vuelve a repetirse. En todo caso es el brote excepcional de una palabra en un contexto de conflicto. 
rras más valiosas, especie de señor feudal de parroquia, que influye y domina soberanamente en el distrito, maneja a sus arrendatarios como a borregos, ata y desata como un San Pedro en caricatura y campea sin rival como el gallo entre las gallinas. El gamonal es pues el sátrapa de la parroquia". ${ }^{16}$

El término es también conocido y utilizado en Colombia después de la primera mitad del siglo XIX. En la región del Cauca, la denominación de gamonal aludía a personajes que ejercen el poder desde los métodos paternalistas de unos a los métodos violentos y expoliadores de otros. Por tanto señala un tipo de dominación local ejercido con mecanismos blandos frente a otro tipo de dominación de carácter despótico. Alonso Valencia identifica como gamonales a los terratenientes que ejercen el poder local por delegación del Estado central en un contexto de partidos políticos nominales que carecen de una estructura real. ${ }^{17}$

Se vuelven a encontrar referencias a su uso en el Ecuador hacia fines del siglo XIX y comienzos del XX. Pero la figura del gamonal, asumió entonces un significado conectado con los sectores en ascenso que habían adquirido un peso reconocible en los pueblos. Se identifica con personajes que han transitado por el empleo de mayordomo, rematista de impuestos y el capital a préstamo. Esta caracterización apareció en la literatura costumbrista y evidencia el malestar que había producido en las aristocracias provincianas el surgimiento de sectores ascendentes en la sociedad rural, a consecuencia de una nueva dinámica mercantil al finalizar el siglo XIX. ${ }^{18}$ Específicamente las descripciones costumbristas se remiten a ciertas zonas de la sierra central ecuatoriana donde emergieron estratos acomodados de campesinos como resultado de una expansión de los mercados locales y regionales.

Alfredo Espinosa Tamayo, en Psicología y Sociología del pueblo ecuatoriano (1918), usa el término gamonal como equivalente a cacique. Y al hablar de caciquismo, indiferentemente de su existencia en la sierra o en

16 Esta definición, había aparecido en la Revista Americana de Lima, y citada por Pablo Macera, se recoge en el libro de Burga, Manuel y Flores Galindo Alberto: Apogeo y crisis de la República Aristocrática, Ed. Rikchay Perú, Lima, 1979, pág. 106, donde también se proporcionan otros detalles relativos al gamonalismo en el sur andino del Perú.

17 Valencia, Alonso: Estado soberano del Cauca. Federalismo y regeneración, Banco de la República, Bogotá, 1988, págs. 178-179

18 Esta caracterización se halla en la literatura costumbrista. Puede verse en este sentido al relato de Martínez, Anacarsis: "Las desilusiones de un gamonal", Revista Guayaquil, Vol. II, n. ${ }^{\text {ss }} 61$ y 62, 1892; de Martínez, Luis A.: el relato "El Doctor", publicado en Disparates y Caricaturas, 1903, Ambato, págs.6-49. 
la costa ecuatorianas, describió dos modalidades de ejercicio del poder local: como prolongación del poder de la propiedad rural y ligada al capital comercial. ${ }^{19}$

De este modo, un gamonal podía ser un mediano propietario, con suficiente influencia, independientemente de que ejerciera o no algún cargo de representación como el de teniente político, o juez parroquial. Los relatos costumbristas se encargaron de difundir esta idea del gamonal: un campesino acomodado o un mediano propietario que cumple funciones de mando en una cabecera de parroquia, tan indispensable para lograr los votos en las contiendas electorales como para mantener bajo control a los indígenas. El gamonal era entonces el poderoso que gozaba de una autonomía parroquial, aunque subordinado política y socialmente a las aristocracias regionales. Era una figura de la política parroquial, producto del ascenso social, donde lo político se mostraba directamente relacionado a los mecanismos de funcionamiento económico y expresaba el vínculo que unía la mediana propiedad rural con ciertas formas del capital comercial. Es decir, el gamonal era alguien que representaba la falta de separación entre lo privado y lo publico existente en el agro.

El lento proceso de formación del Estado ecuatoriano a partir de 1830, tuvo dos componentes fundamentales: la centralización del aparato estatal y una difusión territorial del poder con el desarrollo de la división político administrativa. Simultáneamente a la centralización de una pequeña maquinaria burocrático militar se produjo la expansión de las bases del poder local a partir de la creciente división político administrativa en parroquias y cantones. La lógica de esto era encapsular a los grupos étnicos dentro de un ámbito de poder local y regional, constituyéndose espacios de carácter molecular donde se construyeron las relaciones entre indígenas, pueblos mestizos y haciendas, transformando el estatuto colonial de los grupos étnicos, sobre todo en cuanto a una tendencia observable durante el siglo XIX de recortar las atribuciones y funciones de autoridades étnicas, frente a un nuevo tipo de funcionario del estado a nivel local: el teniente político.

El escalón más bajo de la división político administrativa que constituyó al Estado ecuatoriano después de 1830 era la parroquia. Ésta consistía en un centro poblado, cabecera de parroquia, con autoridades civiles blancas y mestizas, que tenía un control jurisdiccional sobre las áreas rura-

19 Espinosa Tamayo, Manuel: Psicología y sociología del pueblo ecuatoriano, Banco Central del Ecuador, Quito, [1918] 1979, págs. 275-281. Su razonamiento, se halla bastante cercano al de Joaquín Costa, y probablemente haya sido influido por éste. 
les donde residían los indígenas. Los procedimientos más prácticos habían determinado que el área de influencia de una parroquia fuera dividida en partidos, o también en anejos. El cantón era la unidad administrativa intermedia que agrupaba las parroquias, y la provincia la unidad territorial mayor que agregaba los cantones.

La abolición del tributo indígena en 1857, significó una redefinición de la república de los indios y sus papeles en la sociedad. Ocurrió un cuestionamiento del sistema de autoridad indígena, la pérdida de sus reglas de gobierno interno y la progresiva imposición de las normas legales y los procedimientos administrativos del Estado. ${ }^{20}$ En la lógica estatal, se empieza a construir la figura de la igualdad jurídica, o más precisamente de una incorporación formal del indio a la ciudadanía, a partir de la supresión del tributo, en la medida que los indígenas dejaron de tener un estatuto específico ente la ley y los aparatos estatales. Pero en términos prácticos, se hallaban excluidos de la participación electoral.

Hace falta precisar el mayor condicionamiento que tenían los conflictos agrarios y étnicos. Se trata de una situación colonial que sobrevive en la época republicana, con la vigencia de la diferenciación que supone una estructura de castas. El término casta como equivalente a raza y grupo étnico, es el que sirve para definir la ubicación de los sectores sociales en la colonia. En su origen, el término casta se utilizó para denominar a las combinaciones raciales que tenían como referencia a los negros, y equivalía al mestizaje proveniente de lo indígena. ${ }^{21}$ Por eso, las castas en el lenguaje colonial, son los grupos mestizos de origen negro e indígena. El lenguaje de castas, tiene como punto de partida la república de los españoles y la república de los indios, donde cada grupo tiene su propia configuración interna y sus reglas de funcionamiento. En medio de esta oposición de naturaleza étnica, se ubica el complejo mundo mestizo urbano y rural. Pero los grupos dominantes también se constituyen como castas, en cuanto su condición blanca - por oposición - les ubica en otro extremo.

Cuando los grupos étnicos son encerrados en el siglo XIX dentro de ámbitos parroquiales, las castas adquirieron una concreción local. Estas tomaron un sabor localista, con barreras muy rígidas, apoyadas en la dominación étnica. La hegemonía que adquirían las aristocracias regionales

20 Guerrero, Andrés: “Curagas y tenientes políticos. La ley de la costumbre y la ley del Estado (Otavalo 1830-1875)", Revista Andina, vol. 7, n. ${ }^{\circ}$ 2, Cusco, 1989,.

21 Flores Galindo, Alberto: Aristocracia y plebe. Lima, 1760-1830, Mosca Azul Ed., Lima, 1984, pág. 198. 
tenían en el plano local una diferenciación étnica, también molecular. En los niveles locales de la sociedad rural se concretaba la separación y dominación entre la república de los criollos y la república de los indios.

La rudimentaria maquinaria político burocrática de la sociedad pueblerina blanco mestiza, estaba conformada por el teniente político y los jueces parroquiales, a los que se sumaron el instructor escolar, el cura párroco y los tinterillos. Estos personajes coexistían con los mayordomos de haciendas, los rematadores de diezmos y los medianos propietarios, conformando la cúpula de los notables de esa sociedad rural. Difícilmente podría hablarse de una separación estricta entre varios tipos de actividades, porque estas ocupaciones y cargos eran intercambiables.

La "política" en la época, se evidenciaba a través de un complejo juego de facciones que, desde lo local, incidía y canalizaba las lealtades hacia los hacendados nobles residentes en las capitales de provincia o en las cabeceras de cantón. Todo ello en medio de la exclusión de la participación política formal de la población indígena. En el siglo XIX la participación electoral osciló entre el 3\% y el $6 \%$ de la población total del país. Tan tarde como en 1933, esa participación fue del 3\% otra vez, y sólo se amplió al $10 \%$ de la población en $1950 .{ }^{22}$ Esto ilustra cómo sólo una ínfima minoría de la población se vinculaba por el sufragio. Hay pues un gran interrogante acerca de la legitimidad de procesos electorales con tan escasa participación.

El gamonalismo adquiría un significado objetivo de acuerdo a las distintas estructuras agrarias donde estaba presente. Era una de las manifestaciones de la dominación étnica y su mayor atributo era el ejercicio despótico del poder local. Por eso el teniente político, en cuanto encargado de movilizar trabajadores para las obras públicas, utilizando muchas veces elementos compulsivos, o por cumplir el papel de juez de instrucción en las disputas entre blancos e indios, peones indígenas y hacendados se convirtió en una de las figuras principales de la estructura gamonal. Por otra parte, su presencia se tornó cada vez más decisiva a medida que se laicizaba el Estado, después de la revolución liberal ocurrida en 1895.

Después de 1902, los tenientes políticos asumieron también las funciones de registro civil, sobreponiéndose a las funciones que tradicionalmente llevaba adelante la iglesia católica (inscripción de nacimientos y

22 Maiguashca, Juan: "El proceso de integración nacional en el Ecuador: el rol del poder central, 1830-1930, en Maiguashca, J. (ed.), Historia y región en el Ecuador 1830-1930, FLACSO-CERLAC-CEN, Quito, 1994, pág. 399. 
defunciones, matrimonios). Con la reanudación de formas similares al trabajo subsidiario, formalmente derogado en 1895 , los tenientes políticos adquirieron también una capacidad coercitiva ligada a las obras públicas. ${ }^{23}$ En efecto, su reimplantación se organizó bajo la forma de decretos específicos de obras públicas de carácter cantonal o parroquial. La población adulta debía entregar dos jornadas anuales de trabajo o el pago de una contribución monetaria (un sucre), cuando no se cumplían las obligaciones laborales. De este modo, puede decirse que el liberalismo, consolidó el poder de los tenientes políticos.

Casagrande y Piper, en un excepcional estudio sobre los cambios en el poder en la parroquia San Juan de Chimborazo, reconstruyeron lo que fue la estructura de poder parroquial hacia 1910-1920 y lo que ocurrió después en los años sesenta. Con un matiz u otro, su análisis del poder local podría ser similar al de otras parroquias de la sierra donde había una relativa importancia de la hacienda como núcleo dominante en la estructura agraria.

\begin{abstract}
"En la cabecera el teniente político y sus empleados tienen las oficinas administrativas, las judiciales y la cárcel. El convento, la iglesia y el cementerio de la parroquia, todos ellos bajo el control del cura, están ubicados en la cabecera. El apu, también, reside en la cabecera. En ella también se encuentran otros especialistas, incluso los músicos que tocan en las fiestas de la parroquia, y los kishkas, pueblerinos que hablan quichua y sirven de intermediarios a los indios en cuestiones legales, disputas frecuentes sobre herencias o en pendencias personales con otros indios. San Juan tiene un pequeño número de tendejones que venden artículos de consumo y hay, además, un mercado dominguero que sirve tanto a los aldeanos cuanto a los pueblerinos. En la cabecera se vende el aguardiente o trago y se hace y vende chicha en numerosas chicherías. Por cerca de treinta años San Juan tuvo la única escuela en la parroquia y a ella asistía un puñado de niños indios de los anejos". ${ }^{24}$
\end{abstract}

En este ambiente, como dicen Casagrande y Piper, en una feliz frase, "Las llaves del reino de los cielos las tenía firmemente en sus manos el cura y las llaves del reino de la tierra el hacendado y el teniente político" ${ }^{25} \mathrm{La}$ cabecera de parroquia es un centro político y comercial, en el que residen blancos y mestizos, mientras que los anejos a los que se halla vinculada la cabecera parroquial, son de residencia indígena. Una situación como la

23 Acerca de las relaciones y actores involucrados en las obras públicas, ver Clark, Kim: “Los indios, el estado y la ley: los trabajos públicos y la pugna por el control de la mano de obra en el Ecuador del período liberal", Memoria, N. ${ }^{\circ} 4$, Quito, 1994, págs. 53-86.

24 Casagrande,Joseph y Piper, Arthur : "La transformación estructural de una parroquia rural en las tierras altas del Ecuador”, América Indígena, vol. XXXIX, n. 4, México D.F., 1969, págs.1040-41.

25 Ibídem, pág. 1044. 
descrita, se mantuvo hasta los años sesenta. La figura recurrente del tríptico del poder local constituido por el cura, el hacendado y el teniente político, es una imagen que plantea un poder relativamente cerrado, en el que se hallan atrapados los indígenas. El pilar de este orden era indudablemente la hacienda.

\begin{abstract}
"La figura dominante era la del hacendado. Su poder emanaba del control casi exclusivo que tenía sobre los recursos de la parroquia y de sus contactos con funcionarios gubernamentales y superiores de gran influencia. En el dominio de su propiedad era virtualmente absoluta su autoridad. Las demandas de trabajo se cumplimentaban a través de la jerarquía del administrador, los mayordomos y mayorales de la hacienda. Un indio recalcitrante o rebelde fácilmente era castigado. El acceso a los recursos de la hacienda le podían ser vedados o se le imponían tareas adicionales. En casos de agravios mayores como el robo, un indio podía ser azotado, encarcelado o puesto en el cepo. Hay evidencia de indios que morían después de ser golpeados por el hacendado mismo. Los indios no tenían recurso a ninguna otra autoridad ni fuera ni dentro de la parroquia. El hacendado tenía en el bolsillo tanto al cura cuanto al teniente político, a través de su munificencia y debido a su ascendencia con los funcionarios superiores". ${ }^{26}$
\end{abstract}

La figura que completa esta estructura de poder local es el apu, un intermediario local que podía tener ancestro indígena. Los apus pueblerinos, ligados frecuentemente por lazos de compadrazgo con los indígenas, eran un decisivo eslabón en la trama del poder local.

Conviene matizar esta visión de la hacienda, en tanto era un mundo muy complejo en el cual se tejían un conjunto de relaciones materiales y simbólicas en las que se hallaban entrecruzadas las vida de los peones, con sus relaciones laborales, ciclos de vida y fiestas. Una situación en la que operaba una comunidad de huasipungueros que establecía una serie de rituales que le vinculaban al patrón y su poder. ${ }^{27}$

Sin embargo, fue en los momentos finales del liberalismo en el poder a mediados de los años veinte, cuando los mecanismos compulsivos del ejercicio del poder local, se verían reforzados. Si por una parte, la abolición de la prisión por deudas en 1918, presenta el lado benefactor del liberalismo al suprimir la coacción jurídica del concertaje, por otra se prohibían simultáneamente las fiestas indígenas. Además, al crearse las Juntas de Fomento Agrícola se daba control y atribuciones a las aristocracias regionales sobre los indígenas. Estas juntas se hallaban constituidas por el Jefe Político que cumplía las funciones de Presidente, dos concejales, un

26 Ibídem, pág. 1045.

27 Guerrero, Andrés : La semántica de la dominación, Ed. Libri-Mundi, Quito, 1991. 
comerciante y un agricultor (un hacendado). ${ }^{28}$ Instauradas para ejecutar la Ley de Fomento Agrícola e Industrial, se encargaban de proyectar la realización de caminos vecinales, recogían las contribuciones en jornales o en dinero y movilizaban la mano de obra, subordinando a las autoridades parroquiales.

Otro aspecto que daba poder y control a las noblezas regionales fue la legislación de aguardientes, que se caracterizaba por dar en remate los impuestos del aguardiente por provincias y cantones, lo que permitía un manejo de su circulación y un monopolio privado de ámbitos regionales, creando mercados cautivos, lo que ocasionaba fuertes enfrentamientos con los pequeños productores que eludían el control que ejercían los rematadores del estanco de ese producto. Esta legislación, que creaba fuertes privilegios, entró en vigencia precisamente a partir de la década de 1910.

En 1921 se expidió una Ley de abigeato, que castigaba el robo de ganado, delito rural creciente en toda la sierra desde 1915, con la deportación al penal de las Islas Galápagos. La persecución del abigeato, coincide con un nuevo período de conflictividad entre haciendas y comunidades. Las autoridades encargadas de juzgar el abigeato - se señala en un alegato por la derogatoria de la ley-, estaban "casi siempre bajo la influencia de los gamonales". ${ }^{29}$ De allí, que este conjunto de cambios institucionales y legales, pusieran de modo visible a los sectores dominantes regionales como los auténticos detentadores del poder, cambiando el sentido que había adquirido la noción de gamonalismo en el siglo XIX.

Pero persistía el modo de llamar gamonales a los habitantes pueblerinos. Por ejemplo, la nobleza terrateniente que controlaba la Junta de Fomento Agrícola de Ambato tenía muchas dificultades para movilizar la mano de obra mestiza en la construcción de caminos vecinales. Y es así que en 1922, se habla de gamonales, para referirse a los habitantes blancos de San Bartolomé, un pueblo cercano a Ambato, quienes se opusieron a una medida que provenía de la Junta, según comenta uno de los directivos: “... la mayor parte de los blancos o gamonales del pueblo de San Bartolomé no han prestado su contingente en el trabajo de caminos contribuyendo con los dos jornales de Ley o su

28 "Ley de Fomento Agrícola e Industrial", Registro Oficial, 31-X-1918.

29 El Día, 27-VII-1924, Quito. En rigor, el abigeato ya era un tipo de criminalidad rural conocido en el siglo XIX, por ejemplo, para la provincia del Azuay, se menciona “...los delitos más comunes en la provincia de mi mando son el de abigeato y heridas. El primero causado mas por la pobreza, por la falta de educación moral y religiosa de la clase indígena, y el segundo por la embriaguez, prostitución y vagancia, que han cundido en el país".(Informe del Gobernador del Azuay, 1858, en Informe del Ministro del Interior, 1858, pág. 55 
equivalente" ${ }^{30}$ Es decir, un grupo de pueblerinos, se había resistido a una obligación estatal, mediada en este caso por la aristocracia local de Ambato.

Desde los años veinte, por obra del liberalismo radical, el indigenismo y el naciente pensamiento socialista, los gamonales fueron identificados con la clase terrateniente regional. En esos extraños giros de la historia, el gamonal se transformaba en un personaje proveniente de las noblezas regionales, pero que ahora estaba en la gobernación de provincia o en el Concejo Municipal, es decir, en los niveles superiores del ejercicio del poder local. ${ }^{31}$ La lucha política y la novela indigenista de los años treinta, no hicieron sino confirmar el significado nuevo del gamonalismo: el ejercicio del poder local por parte de las aristocracias regionales. La célebre novela de Jorge Icaza, Huasipungo (1934), traza un cuadro impresionista del tríptico del poder local rural, que pone el acento en la figura despótica del hacendado, planteando una visión alternativa a la anterior percepción costumbrista del gamonal. Hasta los años sesenta el término formó parte del repertorio discursivo de la izquierda y del progresismo liberal para caracterizar a la derecha política. Formó parte sustancial, por ejemplo, de los recursos del lenguaje utilizados por Velasco Ibarra, sobretodo durante la campaña electoral de 1960. Los términos gamonalismo y gamonal se convierten en términos catalizadores de su discurso y eran sobretodo maneras de mencionar al gobierno socialcristiano de Camilo Ponce. Los diferencia, sin embargo, de la noción de oligarquía, otro de los conceptos catalizadores típicos de sus arengas políticas. ${ }^{32}$

\section{Una observación sobre el gamonalismo en el Perú}

Como se mencionó antes, el gamonalismo ya había sido en el Perú objeto de discusión en la segunda mitad del siglo XIX. Pero su mayor uso

30 Archivo del Registro Civil de Ambato. Intervención del Sr. Sevilla. Sesión del 5-III-1922. Libro de Actas de la Junta de Fomento Agrícola empezada en noviembre de 1920, Ambato (subrayado nuestro).

31 La definición dada por Alejandro Mateus es bastante escueta, alude a un significado del notable pueblerino, sin asociarlo a la propiedad hacendaria y como sinónimo de cacique: "Gamonal, sujeto que es o se tiene por principal en un pueblo, aldea. Cacique". Mateus, Alejandro: Riqueza de la lengua castellana y provincianismos y ecuatorianismos, Editorial Ecuatoriana, Quito, 1933, pág. 173.

32 La campaña electoral de 1960, expresó una radicalización del discurso de Velasco Ibarra que incluyó el tema de la reforma agraria y las demandas campesinas. Una versión de los discursos de esa campaña está recopilada por Tamayo Mancheno, Gustavo: El velasquismo (Una interpretación poética y un violento período de lucha), Royal Print, Guayaquil, 1960. Referencias específicas sobre gamonalismo y gamonales, en págs. 110 y 250. 
provino del indigenismo a partir de la primera década del siglo XX. Alcanzó una síntesis en el planteamiento expuesto por Mariátegui en Siete ensayos de interpretación de la realidad peruana (1928), quien concebía al gamonalismo como una forma despótica de poder que se sustentaba en el predominio del latifundio en la sociedad rural y la opresión indígena. Se inscribía en una forma ya muy arraigada de ver el problema.

“El término 'gamonalismo' no designa sólo una categoría social y económica: la de los latifundistas o grandes propietarios agrarios. Designa todo un fenómeno. El gamonalismo no está representado sólo por los gamonales propiamente dichos. Comprende una larga jerarquía de funcionarios, intermediarios, agentes, parásitos, etc. El indio alfabeto se transforma en un explotador de su propia raza porque se pone al servicio del gamonalismo. El factor central del fenómeno es la hegemonía de la gran propiedad semifeudal en la política y el mecanismo del Estado. Por consiguiente, es sobre este factor sobre el que se debe actuar si se quiere atacar en su raíz un mal del cual algunos se empeñan en no contemplar sino las expresiones episódicas o subsidiarias". ${ }^{33}$

La interpretación de Mariátegui, correspondía a un clima general de cuestionamiento a la hacienda, como producto del despliegue que adquiere el indigenismo y el comienzo de una nueva política estatal protectora hacia la población indígena en los años veinte en el Perú. Pero su análisis, va más allá, al involucrar en el gamonalismo a otros intermediarios, incluyendo indígenas aculturados.

La imagen del gamonalismo en el Perú, ha estado asociada frecuentemente a la propiedad terrateniente. Proviene de una hecho llamativo, la existencia de grandes latifundios que podrían tener de 100.000 a 200.000 hectáreas de extensión en los casos de más escandalosa concentración y pone el énfasis en el hecho de que amplios territorios habían sido sustraídos del control del Estado, y tenían su propio régimen interno sociopolítico de funcionamiento. Un censo de 1876, reveló que en 3.867 propiedades rurales identificadas como haciendas, residían 373.355 habitantes, que equivalían al 24.7 por ciento de la población rural. ${ }^{34}$

Se asume que el gamonalismo, era la cara local del Estado oligárquico, que en la época posterior a 1880, requirió de sectores dominantes del interior para ejercer la dominación. Según Florencia Mallon, "el Estado oligárquico y modernizante que se consolidó en Perú a finales del siglo XIX

33 Mariátegui, José Carlos: "El problema del indio", en 7 Ensayos de interpretación de la realidad peruana,[1928], Ed. Amauta, Lima. 1964, 9a. ed., págs. 33-34.

34 Klaren, Peter: "Los orígenes del Perú moderno, 1880-1930", en Bethell, Leslie (ed.), Historia de América Latina, vol. 10, Ed. Crítica, Barcelona, 1992, pág. 264. 
se basó en la refragmentación étnica del territorio, entre costa blanca, mestiza y negra, y sierra indígena. El gamonalismo, notoria variante peruana del caudillismo, tomó impulso a partir de la necesidad del Estado limeño de controlar las poblaciones serranas, no directamente a través de su integración a un proyecto nacional, sino indirectamente por vía de los gamonales terratenientes o comerciantes que, a cambio del apoyo represivo del Estado, garantizaban la lealtad política de "sus" zonas". ${ }^{35}$

Un análisis más específico de este período es el de Nelson Manrique. El propone entender al gamonalismo como un poder despótico que se constituye a causa de la violencia con la que tiene que operar el capital mercantil. Su estudio sitúa como marco las zonas altas de Arequipa en la época de la producción de la lana de alpaca que era obtenida de los indígenas mediante mecanismos compulsivos. El control de la lana de alpaca, que era un importante producto de exportación, creaba una cadena de subordinación desde la oligarquía arequipeña hacia los gamonales del interior de la región. El gamonalismo consistía en el empleo de trabajo indígena para servicios personales y obras públicas y era un instrumento privilegiado para concentrar la propiedad de la tierra y la violencia en el proceso de circulación mercantil. Manrique anota que la violencia no era solo dirigida hacia los indígenas, sino que se daba entre las familias o incluso al interior de las familias gamonales. Para ello era importante tener algún cargo de representación política. La debilidad del Estado central, tenía como contrapartida un poder gamonal fuerte. ${ }^{36}$

En la situación específica de Caylloma, Manrique afirma que el gamonalismo precedió a la formación del latifundio y fue también un instrumento para la consolidación de la gran propiedad. Así mismo, había gamonales que no tenían vinculación con la propiedad de la tierra. ${ }^{37}$

Un planteamiento que propone otra dirección para el estudio del gamonalismo es el de Deborah Poole. Ella sugiere que en Chumbivilcas, una provincia cusqueña de difícil acceso, sería la muestra de que incluso en una época posterior a la reforma agraria, en los años ochenta del siglo pasado, "los gamonales aún ejercen un tremendo poder", que "se realiza mediante mecanismos tan diversos y complejos como el abigeato, los prés-

35 Mallon, Florencia: "Entre la utopía y la marginalidad: comunidades indígenas y culturas políticas en México y los Andes, 1780-1990”, Historia Mexicana, vol. XLII, n. ${ }^{\text {2 }, ~ 1992, ~ M e ́ x i c o ~ D . F ., ~}$ pág.483.

36 Manrique, Nelson: "Gamonalismo, lanas y violencia en los Andes", en Urbano, Henrique (comp.), Poder y violencia en los Andes, Centro Bartolomé de las Casas, Cusco, 1991, págs. 211-223.

37 Ibídem, pág. 219. 
tamos bancarios, la política electoral, la educación, las fiestas y el folklore, en especial el astuto manejo del ideal cultural o folklórico del vaquero solitario y macho". ${ }^{38}$ Se trataría de una compleja interrelación entre una cultura provinciana, elementos de la cultura campesina, discursos oficiales e indigenismo que han configurado la mentalidad gamonal. Las condiciones de persistencia de está forma despótica, se hallan dadas por la existencia de zonas aisladas de la sierra peruana.

Poole usa la expresión gamonal sin darle un contenido social específico. Se refiere de manera general a los notables del pueblo, sean o no autoridades locales. Un ejemplo histórico de su análisis, es que las estructuras gamonales de poder podían oponerse al avance del estado moderno en áreas específicas clave. Así a fines del siglo XIX, cuando el Estado trataba de introducir mecanismos modernos de contribución e impuestos que afectaban a la población blanca e indígena, se produjo una alianza con los indígenas para oponerse a su penetración. ${ }^{39}$ Pero lo más sorprendente, es que según Poole, el gamonalismo y los gamonales, seguían en los años ochenta del siglo XX teniendo importancia en zonas altas del Cusco, a través del control de la política local y los ciclos festivos, en los que se evidenciaba la violencia real y simbólica en la relación con los indígenas. ${ }^{40}$

\section{A modo de conclusión}

El término gamonal que emergió en la segunda mitad del siglo XVIII era posiblemente una manera de caracterizar a personajes que tenían un papel de mando en la cúspide de la sociedad. Su utilización, y luego su anclaje en la lucha política, lo convirtieron en un concepto con significados distintos según el sector o grupo social que lo utilizaba para identificar una oposición antagónica. La factibilidad de entender el gamonal y el gamonalismo no sólo como figuras retóricas sino como actores y formas de ejercicio del poder local, aparece como un desafío para entender las estructuras

38 Poole, Deborah: "El folklore de la violencia en una provincia alta del Cusco", en Urbano, Henrique, (comp.): Poder y violencia en los Andes, Centro Bartolomé de las Casas, Cusco, 1991, págs. 277-297.

39 Ibídem, pág. 298.

40 Durante la década de 1980 se produjo una aguda fase de violencia política en la sierra peruana por la insurgencia del movimiento armado "Sendero Luminoso". En las representaciones de los grupos teatrales afines a SL, uno de los sujetos que parece en los dramas es el gamonal como contrincante de los campesinos. Ver Salazar, Hugo: "El teatro peruano de los 80", Márgenes, núms. 5-6, Lima, 1989, págs. 74-75. 
del Estado ecuatoriano en los siglos XIX y XX. Más ampliamente, comprender los modos de vigencia de las formas patrimoniales de dominación que han impregnado la formación histórica del Estado ecuatoriano.

Según Michael Mann, el desarrollo histórico del Estado centralizado, tiene un componente despótico y otro de naturaleza infraestructural. El aspecto despótico es "el abanico de acciones que la elite tiene facultad de emprender sin negociación rutinaria, institucional, con grupos de la sociedad civil". Mientras que el poder infraestructural es "la capacidad del Estado para penetrar realmente la sociedad civil, y poner en ejecución logísticamente las decisiones políticas por todo el país" ${ }^{41}$ Las formas locales de dominación son una combinación de ambos aspectos, dado que implican el desarrollo de una capacidad de administrar poblaciones étnicas con una mezcla de despotismo y limitado poder infraestructural del Estado.

El período histórico de esplendor del gamonalismo se extiende desde mediados del siglo XIX hasta las reformas agrarias. Se correspondió con un Estado que tenía ampliamente descentralizado el ejercicio del poder local, en función de estructuras sociales y étnicas basadas en la desigualdad.

Tal situación se modificó después de los años sesenta del siglo XX con los cambios agrarios que afectaron al antiguo poder terrateniente y cuando el Estado desarrollista promovió una forma distinta de intervención en el agro, lo que condujo a que sus distintos aparatos y agencias redefinieran su vínculo con la población indígena. Adicionalmente, en diversos lugares de la sierra ecuatoriana, la Iglesia católica, uno de los pilares del antiguo orden local, optó por el apoyo a los grupos indígenas. Se produjo de este modo, una erosión de la administración étnica. Los cambios en la estructura agraria, con las reformas agrarias de 1964 y 1973, determinaron la crisis y disolución del antiguo orden rural. La hacienda se vio muy afectada en su función tradicional de soporte de las estructuras locales de poder: "Desaparecido ese soporte nodal de la dominación étnica, se abre un vacío de poder en las parroquias rurales de la Sierra donde, al cabo de casi tres décadas, aparece finalmente un conglomerado heteróclito de instituciones públicas, pero no estatales, que se autocalifican de "indígenas" y consolidan una suerte de sociedad civil de tipo rural y étnica"..$^{42}$ La creación de parroquias indígenas y el nombramiento de tenientes políticos indígenas en distintos lugares de la sierra ecuatoriana después de 1970, lo que impli-

41 Mann, Michael: "El poder autónomo del Estado: sus orígenes, mecanismos y resultados", Zona Abierta, n.os 57/58, Madrid, 1991, págs. 19-20.

42 Guerrero, Andrés: "El levantamiento nacional de 1994”, Memoria, n. o 5, Quito, 1996, pág. 94. 
caba la ocupación de cargos sólo detentados antes de los cambios agrarios por blancos y mestizos permitió el afianzamiento del protagonismo indígena en ese nivel. Ello ocurrió en el marco de unos conflictos agrarios y étnicos que tuvieron lugar durante un período de modernización estatal.

Finalmente la Constitución de 1978, al extender el sufragio a los analfabetos, eliminó la barrera que impedía el ejercicio del voto a amplios sectores rurales indígenas. Con el inicio del período democrático de 1979, comenzó también una participación inicialmente limitada de candidatos indígenas a cargos de representación local, proceso que se consolidó después de mediados de la década de 1990 con un acceso a gobiernos locales en zonas de habitat indígena. ${ }^{43}$

Esta claro que el gamonalismo como forma de poder descentralizada funciona paralelamente en una época en que el Estado nacional hace un esfuerzo por centralizar sus políticas, construyendo un aparato estatal nuclear con ramificaciones regionales y locales. Un aspecto central del gamonalismo era la administración étnica, que tenía como su pieza clave el poder delegado que había conferido el Estado central al teniente político. Cuando la dominación étnica entra en crisis, por efecto de la ampliación de la capacidad infraestructural del Estado y procesos de cambio agrario, el gamonalismo emprende la retirada. Ese poder, queda vacante, adquiere características fantasmagóricas y pasa a ser ocupado y construido por los sujetos que habían estado dominados. Pero eso, ya es otra historia.

43 Ibarra, Hernán: Participación política indígena y cambios en el poder local, IBIS, Quito, 1997 (inédito). 